\title{
LIÇÕES APRENDIDAS DE GRANDES INCÊNDIOS EM ESTRUTURAS DE CONCRETO
}

\author{
A. BERTO \\ Pesquisador do Laboratório de Segurança ao Fogo e a Explosões do IPT, São Paulo, Brasil
}

\section{RESUMO}

A segurança contra incêndio é um objetivo que deve ser perseguido durante todas as etapas envolvidas no processo produtivo e no uso do edifício. Deve ser considerada desde a concepção e o desenvolvimento do anteprojeto do edifício, passando pelo projeto e construção e adentrando a fase de operação e manutenção. Na fase de projeto, a questão deve ser especialmente considerada, pois aí se estabelece a estrutura básica da segurança contra incêndio do edifício; ele deve ser elaborado a partir de um conhecimento aprofundado das relações que mantem com as disposições que conferem ao edifício, níveis adequados de segurança contra incêndio. Neste artigo, serão abordados os aspectos normativos com relação a este assunto e apresentados estudos de casos de edifícios que sofreram a ação do incêndio e suas consequências.

Palavras chave: incêndio, projeto, estruturas de concreto.

\begin{abstract}
Fire safety is a goal that must be pursued during all steps involved in the production process and use of the building. It must be considered from the conception and development of the preliminary design of the building, through the design and construction and into the operation and maintenance phase. In the design phase, the issue should be especially considered, as it establishes the basic structure of the building's fire safety; It must be based on a thorough knowledge of the relationships with the provisions that give the building adequate levels of fire safety. In this article, the normative aspects related to this subject will be approached and case studies of buildings that suffered the fire action and its consequences will be presented.
\end{abstract}

Keywords: fire, design, concrete structures. 


\section{INTRODUÇÃO}

O incêndio, atingindo a fase de inflamação generalizada no ambiente de origem, promove gradativamente, em função de sua severidade, a fragilização gradual dos elementos estruturais e assume, em condições críticas, a capacidade de promover o colapso estrutural da edificação. Esta capacidade se amplia na medida em que maiores porções da estrutura são afetadas por sua ação, ou seja, na medida em que o incêndio se propague para outros ambientes.

Por conta disso, os projetos dos elementos construtivos estruturais devem necessariamente considerar a resolução da resistência ao fogo. Atualmente, no Brasil existem regulamentações (estaduais) referentes a essa questão, cujo atendimento no projeto e na construção das edificações é compulsório. Como referência de regulamentação se pode citar o Decreto Estadual $n^{\circ}$ 63.911/2018 do Corpo de Bombeiros do Estado de São Paulo, no qual estão inseridas a Instrução Técnica nº 08/2019 - Resistência ao fogo de elementos da construção e a Instrução Técnica $n^{\circ} 09$ - Compartimentação horizontal e vertical.

A exigência de dotar os elementos estruturais de resistência ao fogo está fortemente vinculada à compartimentação horizontal e vertical das edificações, afinal as lajes, e vigas associadas, sempre integram a compartimentação vertical e as paredes com função de compartimentação horizontal sempre contam com elementos estruturais, incorporados ou não à estrutura principal da edificação.

Na perspectiva da solução integral da segurança contra incêndio, a compartimentação vertical é aspecto que interfere definitivamente na resolução da resistência ao fogo dos elementos estruturais. Certamente será extremamente complexo assegurar (controlar o risco com alto nível de confiança), no desenvolvimento do projeto estrutural, que não ocorrerá a ruína da edificação caso porções amplas da estrutura em diversos pavimentos da edificação sejam submetidas concomitantemente à ação do incêndio.

\section{TEMPO REQUERIDO de RESISTÊNCIA ao FOGO}

O Decreto Estadual n ${ }^{\circ}$ 63.911/2018 do Corpo de Bombeiros do Estado de São Paulo, por meio da Instrução Técnica $n^{\circ}$ 08/2019, estabelece condições a serem atendidas pelos elementos estruturais e de compartimentação das edificações e define os tempos requeridos de resistência ao fogo (TRRF) sob o pretexto de que, em situação de incêndio, seja evitado o colapso estrutural, possibilitando a saída segura das pessoas e o acesso para as operações do Corpo de Bombeiros. Esse TRRF de elementos construtivos estruturais e de compartimentação é condicionado à ocupação e altura da edificação.

O TRRF é um parâmetro de projeto e não representa o tempo de duração do incêndio, tempo de evacuação da edificação ou mesmo tempo de resposta do Corpo de Bombeiros para o início do combate ao incêndio. O TRRF é estabelecido empiricamente, levando em conta a provável severidade do incêndio, as dificuldades de controlar o avanço do incêndio e as consequências do colapso estrutural provocado pelo incêndio, seja em termos de risco às equipes de combate, seja em termos de ocorrência de ruína, considerando a gravidade crescente decorrente da altura da edificação.

Tomando como exemplo a classe de ocupação "edifícios de escritórios", o Decreto Estadual $\mathrm{n}^{\circ}$ 63.911/2018 estabelece valores de TRRF na faixa de $30 \mathrm{~min}$ a $180 \mathrm{~min}$. Para edifícios térreos e de até $6 \mathrm{~m}$ de altura requer $30 \mathrm{~min}$, acima de $6 \mathrm{~m}$ até $23 \mathrm{~m}$ requer $60 \mathrm{~min}$, acima de $23 \mathrm{~m}$ até $30 \mathrm{~m}$ requer 90 min, acima de $30 \mathrm{~m}$ até $120 \mathrm{~m}$ requer $120 \mathrm{~min}$, acima de $120 \mathrm{~m}$ até $150 \mathrm{~m}$ requer $150 \mathrm{~min}$ e acima de $150 \mathrm{~m}$ até $250 \mathrm{~m}$ requer $180 \mathrm{~min}$.

Para esta classe de ocupação a compartimentação vertical é requerida apenas para edificações com altura superior a $12 \mathrm{~m}$. Apesar disso, para edifícios com altura superior a $12 \mathrm{~m}$ (que normalmente apresentam mais de cinco pisos) o referido Decreto admite que tal compartimentação seja substituída (parcialmente, pois faz exceção para selagens de penetrações e fachadas) por sistema de detecção automática de incêndio, sistema de sprinklers e sistema de controle de fumaça (apenas no átrio para 
edifícios com altura até $23 \mathrm{~m}$ ). Acima de $90 \mathrm{~m}$ a compartimentação vertical é, de fato, obrigatória e deve ser acompanhada dos sistemas de detecção, sprinklers e controle de fumaça.

É importante ressaltar que os sistemas de detecção automática de incêndio e de sprinklers já são obrigatórios, respectivamente, para alturas superiores a $12 \mathrm{~m}$ e $30 \mathrm{~m}$, mesmo que a compartimentação vertical tenha sido adotada. Desta forma, não representam para essas situações nenhum benefício adicional em termos de segurança contra incêndio que permitisse eliminar a compartimentação vertical. Pode-se considerar, tendo em conta os valores propostos de TRRF, e as cargas de incêndio típicas para edifícios de escritório ( $700 \mathrm{MJ} / \mathrm{m}^{2}$, segundo o Decreto Estadual n ${ }^{\circ}$ 63.911/2018 do Corpo de Bombeiros do Estado de São Paulo), entre outros fatores, que 60 min seja o valor básico necessário para a estrutura suportar a ação do incêndio. $\mathrm{O}$ valor de $30 \mathrm{~min}$ seria um abrandamento para edifícios de menor porte e os valores de $90 \mathrm{~min}, 120 \mathrm{~min}, 150 \mathrm{~min}$ e $180 \mathrm{~min}$ corresponderiam a agravamentos considerando o que se colocou até aqui. Note-se que tais agravamentos não dão conta do risco de porções da estrutura, associadas a pavimentos subsequentes, estarem submetidos concomitantemente a incêndios de severidades condizentes ao TRRF de 60 min, que representa ação extremamente severa sobre a estrutura.

Apesar disto, o Decreto Estadual no 63.911/2018 do Corpo de Bombeiros do Estado de São Paulo concede benefícios de abrandamento das exigências relativas ao TRRF. Permite a redução do TRRF em 30 minutos por meio de um cálculo de tempo equivalente, que leva em conta (entre outros fatores) a existência de sistema de sprinklers e sistema de detecção automática de incêndio (e que não leva em conta a existência de compartimentação vertical e horizontal). Em muitas situações consideradas, estas medidas de proteção ativas são obrigatórias ou já foram levadas em conta para abolir a necessidade de compartimentação vertical e de compartimentação horizontal. No caso de edifícios de escritórios, tomado como exemplo, aceita-se o tempo equivalente ao TRRF de 30 min para edificações com altura até $23 \mathrm{~m}$. O abrandamento concedido está muito além do razoável, sob o ponto de vista do risco de colapso estrutural em situação de incêndio.

A abordagem aqui descrita se repete para praticamente todos os outros tipos de ocupação. Destaca-se aqui o caso de edifícios de escritório por conta das tragédias ocorridas no Brasil envolvendo essas edificações e pelas ruínas já ocorridas de suas estruturas de concreto.

\section{ABORDAGEM SISTÊMICA DA SEGURANÇA CONTRA INCÊNDIO}

A pouca consistência que a regulamentação, em vigor no Brasil, apresenta em relação a questões que afetam a estrutura das edificações em situação de incêndio, resulta na possibilidade de prevalecerem condições de risco que darão margem à ocorrência de grandes tragédias. Falta nessa regulamentação, em relação ao tema da resistência ao fogo das estruturas, o sentido sistêmico, que se constitui em questão essencial para tornar possível, frente à complexidade da resolução do problema da segurança contra incêndio, a adoção de uma abordagem que conduza a soluções seguras.

Esta abordagem se inicia no projeto e se estende por toda a vida útil da edificação, considerando a subdivisão do problema geral em problemas parciais, que faça frente à complexidade dos riscos, tendo em conta os objetivos traçados. Tal abordagem deve permitir que cada um destes problemas parciais seja resolvido de forma independente, assegurando-se que mantenham entre si interação e sinergia suficientes para estabelecer, de maneira apropriada, a solução da segurança contra incêndio como um todo. Uma proposta razoável para essa subdivisão, que tem sido recomendada pelo IPT como sendo capaz de possibilitar boas soluções de segurança contra incêndio, apresenta oito elementos:

a) Precaução contra o início de incêndio, composto por ações preventivas visando controlar o risco do início do incêndio;

b) Abandono seguro da edificação, composto por ações protetoras visando assegurar o abandono rápido e seguro da população do edifício; 
c) Limitação da ocorrência da inflamação generalizada, composto por ações protetoras visando controlar o risco de rápido crescimento de incêndio no ambiente de origem;

d) Extinção inicial do incêndio, composto por ações protetoras visando garantir os meios para combate ao incêndio em seus estágios iniciais;

e) Limitação da propagação do incêndio dentro na edificação, composto por ações protetoras visando controlar o risco de propagação do incêndio além do ambiente de origem;

f) Precaução contra a propagação do incêndio para edificações adjacentes, composto por ações protetoras visando controlar o risco de propagação do incêndio para edificações adjacentes;

g) Precaução contra o colapso estrutural, composto por ações protetoras visando controlar o risco de ruína total ou parcial da edificação afetada pelo incêndio;

h) Facilitação das operações de combate e resgate, composto por ações protetoras visando garantir rapidez e eficiência das operações de combate.

Cada um desses elementos, com exceção do primeiro, é composto por ações de natureza protetora, ou seja, medidas de proteção contra incêndio, que se dividem em ativas e passivas. As primeiras, com as quais há maior familiaridade no Brasil, correspondem aos sistemas prediais de proteção contra incêndio, abrangendo hidrantes, sprinklers, detecção e alarme etc. As ações passivas, que compõem a porção da proteção contra incêndio associada ao maior número de elementos da abordagem sistêmica mencionada, compreendem o controle das características de reação ao fogo dos materiais empregados nas edificações, a compartimentação horizontal e vertical, a resistência ao fogo dos elementos estruturais etc. e condicionam, especialmente, as soluções dos elementos: abandono seguro da edificação; limitação da ocorrência da inflamação generalizada; limitação da propagação do incêndio dentro da edificação; precaução contra a propagação do incêndio para edificações adjacentes; precaução contra o colapso estrutural; e facilitação das operações de combate e resgate.

Tem-se como um dos objetivos fundamentais da segurança contra incêndio a preservação da estabilidade estrutural da edificação em situação de incêndio. Pode-se atingir esse objetivo de modo mais confiável caso a solução da segurança contra incêndio seja considerada como um todo, a partir de uma abordagem sistêmica.

Um princípio de incêndio que encontre na edificação condições favoráveis para crescer e atingir rapidamente a fase de inflamação generalizada, dificilmente será controlado com o emprego de sistemas manuais de combate. O crescimento rápido do incêndio não deixará tempo para a ação de brigadistas e o ambiente será tomado pela fumaça e pelo calor inviabilizando a presença humana. Uma situação como essa, não protegida por sistema automático de combate (ou em caso de falha desse sistema), poderá permitir a ocorrência de um incêndio, que saia totalmente do controle, a ponto de afetar extensivamente a estrutura da edificação. Sob o ponto de vista da vida humana, as condições favoráveis ao crescimento do incêndio poderão definir tempo insuficiente para o abandono seguro da edificação, surpreendendo as pessoas, que poderão ser afetadas pela fumaça e calor que são desenvolvidos no incêndio em proporções assustadoras, quando a inflamação generalizada é atingida.

Estes são apenas dois exemplos que justificam plenamente a necessidade da abordagem sistêmica da segurança contra incêndio, que se caracteriza pela interação das soluções de seus elementos com o intuito de resolver o problema da segurança como um todo na edificação. Neste sentido pode-se afirmar que a solução do elemento Precaução contra o colapso estrutural, além de depender de questões intrínsecas à estrutura nas fases de projeto, dimensionamento e execução da estrutura, dependerá de fatores extrínsecos associados a outros elementos do sistema, como Limitação da ocorrência da inflamação generalizada, Extinção inicial do incêndio, Limitação da propagação do incêndio dentro na edificação, Precaução contra a propagação do incêndio para edificações adjacentes e Facilitação das operações de combate e resgate. 


\section{IMPORTÂNCIA DA COMPARTIMENTAÇÃO}

A detecção automática do incêndio e o controle de fumaça não desempenham, diretamente, o papel de conter a propagação vertical do incêndio. O sistema sprinklers, por sua vez, pode fazer isto na medida em que contenha o desenvolvimento do incêndio em seu local de origem. Caso este sistema falhe, ou não conte com as necessárias ações de apoio decorrente do combate manual, o incêndio pode se propagar verticalmente na edificação. De modo geral no Brasil, estes três sistemas apresentam baixa confiabilidade em razão de deficiências de projeto, de instalação, de operação e de manutenção. Diante desta situação, pode-se considerar que a dispensa da compartimentação vertical no projeto de edifícios altos vem a ser uma temeridade.

Caso o edifício não seja dotado da devida compartimentação vertical, o Corpo de Bombeiros terá pouquíssimo tempo e grande dificuldade para conter a propagação vertical encharcando e esfriando os pavimentos superiores. Como agravante desta situação tem-se que o Corpo de Bombeiros no Brasil, de modo geral, tarda a chegar ao local do incêndio.

É necessário reconhecer que a compartimentação vertical de edifícios altos encontra nas fachadas uma grande fragilidade. Essa situação é caracterizada por dois aspectos. O primeiro diz respeito às características de reação ao fogo dos materiais que compõem a fachada. No Brasil, não existem regras para avaliação do comportamento ao fogo da fachada como um todo e as regras para a seleção dos materiais que integram a fachada, com relação às características de reação ao fogo, são relativamente novas e sistematicamente descumpridas. Fachadas em edifícios altos de escritório, por exemplo, são muitas vezes revestidas com painéis de alumínio composto, que apresentam comportamento equivalente àqueles que estavam instalados na fachada da Grenfell Tower, onde o incêndio propagou verticalmente, provocando a morte de mais de 70 pessoas.

O segundo aspecto mencionado é caracterizado pela seguinte situação: o incêndio, atingindo a inflamação generalizada no ambiente de origem, pode se propagar horizontalmente e dominar grandes áreas no pavimento, ampliando com isto o risco de propagação vertical por meio da fachada, já que grande porção da fachada poderá estar sujeita a trocas intensas de calor por convecção, capazes de determinar a propagação do incêndio para pavimentos superiores. Esta condição pode ser atingida mais facilmente em edifícios de escritórios, que tipicamente apresentam plano espacial aberto. Mesmo que existam separações verticais entre aberturas de pavimentos consecutivos compostos, normalmente, pela conjugação da viga de borda e do peitoril, a ausência da ação de combate resfriando a fachada acima do pavimento do incêndio pode ser crucial.

No sentido acima indicado e também por conta da possibilidade de grande porção da estrutura ser atacada simultaneamente por um incêndio que domine todo o pavimento da edificação, a compartimentação horizontal também tem papel muito importante para o desempenho da estrutura.

Se a compartimentação vertical já é mal resolvida na regulamentação, a compartimentação horizontal é ainda mais. Retomando o caso dos edifícios de escritórios, edificações com até $12 \mathrm{~m}$ de altura, podem ter a compartimentação horizontal substituída pela disposição de sistema de sprinklers; acima de $12 \mathrm{~m}$ até $30 \mathrm{~m}$ de altura a substituição deve agregar o sistema de detecção automática de incêndio (apesar do sistema de detecção já ser obrigatório para edificações com altura superior a $12 \mathrm{~m}$ ). Apenas acima de $30 \mathrm{~m}$ de altura não pode haver a substituição da compartimentação horizontal por esses dois sistemas ativos de proteção contra incêndio. A partir dessa altura o sistema de sprinklers passa a ser requerido. Apesar disso, a área de compartimentação horizontal admitida é de $2.000 \mathrm{~m}^{2}$. Ocorre que os sistemas de detecção automática são obrigatórios para alturas superiores a $12 \mathrm{~m}$, mesmo que a compartimentação horizontal tenha sido adotada, não representando para essas situações nenhum benefício adicional.

Não se pode deixar de mencionar que, de acordo com o Decreto Estadual no 63.911/2018 do Corpo de Bombeiros do Estado de São Paulo, quando exigida a compartimentação vertical, será permitida, nos pisos acima do térreo, a interligação de até três pavimentos consecutivos, por intermédio de átrios, escadas, rampas de circulação ou escadas rolantes, desde que o somatório de áreas desses pavimentos 
não ultrapasse os valores estabelecidos para a compartimentação de áreas. Observa-se assim mais uma fragilidade que ameaça o desempenho das estruturas da edificação em situação de incêndio.

O cenário aqui apresentado determina que as estruturas de concreto das edificações, mesmo que tenham sido projetadas para cumprir o TRRF, considerando o dimensionamento dos membros estruturais isoladamente, de acordo com a norma brasileira ABNT NBR 15200:2012 - Projeto de estruturas de concreto em situação de incêndio, podem sofrer ruína quando porções consideráveis do todo são afetadas pelo calor intenso do incêndio. Para agravar a situação, não se pode deixar de mencionar, que a imensa maioria das estruturas de concreto das edificações no Brasil não recebe a atenção devida em relação ao dimensionamento para a situação de incêndio.

A regulamentação de Segurança Contra Incêndio surgiu no município de São Paulo em 1974, poucos dias após o grande incêndio ocorrido no edifício Joelma, onde morreram 179 pessoas. Já vinha sendo preparada após o incêndio no edifício Andraus, com a expectativa de ser incorporada à próxima revisão do Código de Obras e Edificações do Município. A tragédia do edifício Joelma determinou a publicação das regras que haviam sido desenvolvidas, na forma de um Decreto Municipal, propondo que fossem observadas no projeto, construção e uso das edificações. A primeira regulamentação consistente do Corpo de Bombeiros do Estado de São Paulo foi publicada apenas nove anos depois, ou seja, em 1983. Os projetos de edificações elaborados anteriormente a estas datas não eram obrigados a atender quaisquer regras de segurança contra incêndio. Os edifícios antigos em São Paulo, ou seja, aqueles projetados anteriormente à vigência dos Decretos mencionados, de modo geral, não incorporavam medidas de proteção contra incêndio. Apesar disto, a partir do momento em que se estabeleceu a necessidade de que obtivessem o Auto de Vistoria do Corpo de Bombeiros - AVCB (documento emitido pelo Corpo de Bombeiros certificando que, durante a vistoria, a edificação possuía as condições de segurança contra incêndio, previstas pela legislação, estabelecendo um período de revalidação), o Corpo de Bombeiros do Estado de São Paulo criou regras para adaptação deles, de maneira a incorporarem obrigatoriamente, ao menos, um conjunto básico de medidas de proteção contra incêndio. Estas regras, atualmente, estão consolidadas na regulamentação do Corpo de Bombeiros atualmente em vigor, ou seja, no Decreto Estadual n 63.911/2018, sob o título Adaptação às Normas de Segurança contra Incêndio - Edificações Existentes. Os edifícios antigos, por força do Decreto, devem ser regularizados junto ao Corpo de Bombeiros por meio da obtenção do AVCB, ou seja, devem ser dotados de medidas de proteção contra incêndio consideradas básicas, que correspondem a: extintores de incêndio; iluminação de emergência; sinalização de emergência; alarme de incêndio; instalações elétricas em conformidade com as normas técnicas; brigada de incêndio; hidrantes; saída de emergência; selagem de shafts e dutos de instalações, para edificações com altura superior a $12 \mathrm{~m}$. Note-se que não estão incluídas como básicas, entre outras, as exigências de compartimentação horizontal e vertical e nem de resistência ao fogo da estrutura. Desta forma, os edifícios antigos, mesmo detentores do AVCB, podem apresentar estrutura incapaz de suportar a ação do incêndio.

\section{ESTRUTURAS DE CONCRETO EM SITUAÇÃO DE INCÊNDIO}

Muitos projetistas ainda acreditam que a segurança contra incêndio é uma questão menor e que as estruturas de concreto não sofrem, extensamente, danos em situação de incêndio ou, ainda, que o incêndio é um fenômeno extremamente raro que nunca afetará a estrutura que está sendo concebida/projetada e que caso, em situação extrema, o incêndio aconteça, não se tentará associar uma eventual ruína a deficiências de projeto. Tudo isto, associado ao fato de os processos de fiscalização não incluírem a verificação do dimensionamento das estruturas em situação de incêndio, conduz ao não atendimento das regulamentações e normas que impõem como obrigatório a resolução desta questão. Agregue-se a isto o sentimento, muitas vezes determinante, de que o dimensionamento de estruturas de concreto em situação de incêndio seja uma penalização desnecessária, pois conduz à adoção de seções mais amplas e a maiores recobrimentos das armaduras longitudinais. 
De fato, a necessidade de adoção de seções e recobrimentos mais amplos se aplica a algumas situações, o que fica evidente quando se adota o método de dimensionamento tabular incluído na norma ABNT NBR 15200:2012 e se busca atender valores de TRRF superiores a $60 \mathrm{~min}$. Tal método se baseia em tabelas de dimensionamento derivadas de resultados de ensaios de resistência ao fogo e incorpora questões como: preservação de um núcleo resistente de concreto; preservação de temperaturas adequadas da armadura e condições aceitáveis de aderência aço-concreto. Ocorre que a preservação da estabilidade das estruturas de concreto em situação de incêndio vai muito além do que prevê o método tabular, pois outros aspectos importantes interferem no comportamento das estruturas de concreto, quais sejam: o sistema estático da estrutura como um todo; os grandes esforços que surgem na estrutura em situação de incêndio causados por dilatação térmica de partes aquecidas da estrutura; e o lascamento explosivo que o concreto pode sofrer em situação de incêndio.

Em relação aos esforços de dilatação, a norma ABNT NBR 15200:2012 propõe textualmente o seguinte:

"O calor transmitido à estrutura nesse intervalo de tempo (TRRF) gera em cada elemento estrutural, função de sua forma e exposição ao fogo, uma certa distribuição de temperatura. Este processo gera a redução da resistência dos materiais e da capacidade dos elementos estruturais, além de esforços solicitantes decorrentes de alongamento axiais ou de gradientes térmicos. Como com o aquecimento, a rigidez das peças diminui muito e a capacidade de adaptação plástica cresce proporcionalmente, os esforços gerados pelo aquecimento podem, em geral, ser desprezados."

Não é difícil perceber, e os grandes incêndios ocorridos no Brasil que afetaram edifícios com estrutura de concreto evidenciam essa situação, que não ocorre essa perda de rigidez, indicada na norma, da estrutura de concreto na região afetada pelo incêndio e, muito menos, na estrutura como um todo. No interior da seção das peças de concreto, durante o incêndio, parte preponderante da estrutura se mantêm com temperaturas proporcionalmente pouco elevadas. Apesar disso, a porção superficial das peças atinge temperaturas altas, e determina na média, considerando toda a seção e o comprimento das peças, temperaturas suficientes para ocasionar dilatações térmicas extremamente maiores que qualquer capacidade de adaptação plástica da estrutura.

Na realidade as dilatações térmicas dos elementos estruturais, como vigas e pilares, submetidos em três ou quatro faces à ação do incêndio, produzem esforços que a estrutura dificilmente será capaz de absorver, sem gerar, ao menos danos locais (colapsos) graves à estrutura de concreto. O problema da dilatação térmica, em relação ao colapso da estrutura, se acentua nas situações apresentadas abaixo e pode levar a desastres:

a) Os esforços são, predominantemente, direcionados para um setor da estrutura, em razão da grande rigidez do setor oposto da edificação, que oferece reação aos esforços sem sofrer deformação significativa;

b) Os esforços são predominantemente direcionados para um setor da estrutura, em razão da disposição assimétrica de pilares ou vigas;

c) Os esforços são, predominantemente, direcionados para pilares que integram pórticos múltiplos, em que as vigas entre eles vençam grandes vãos e que, consequentemente, tenham grande seção;

d) O reticulado estrutural não apresenta grande rigidez, ou seja, apresentam baixo grau de hiperestaticidade, como as estruturas pré-moldadas, onde os elementos horizontais e verticais pré-fabricados são solidarizados na obra, e os esforços de dilatação deslocam os apoios.

Quando mais que uma destas condições coexiste a situação pode tornar-se crítica e a ruína total ou parcial da edificação pode ocorrer. Esta situação pode ser alcançada prematuramente na situação de incêndio, ou seja, antes mesmo que os efeitos do calor determinem danos locais que proporcionem o colapso dos elementos estruturais diretamente afetados pelo incêndio. 
A situação parece se agravar quando a estrutura horizontal é composta por lajes nervuradas, que apresentam em relação às lajes planas maior superfície de transferência de calor. Uma superfície muito mais significativa e enrijecida de concreto atinge temperaturas elevadas, antes que sofra danos mecânicos significativos, ou seja, enquanto ainda tem condições de transferir esforços de dilatação para os elementos estruturais aos quais são vinculados (vigas e pilares). Correspondem a esforços transversais cortantes para os quais esses elementos estruturais não estão preparados para suportar.

O concreto exposto ao calor intenso, em situação de incêndio, sofre alterações físico-químicas que comprometem decisivamente suas propriedades mecânicas. As armaduras no interior das peças de concreto, aquecidas gradativamente, tem sua aderência com o concreto comprometida e, ainda, sofrem redução significativa do limite de escoamento. Ainda, o problema da fragmentação superficial pode promover a redução da seção transversal das peças e, consequentemente, de sua capacidade portante, além de poder expor as armaduras diretamente às altas temperaturas alcançadas em um incêndio. $\mathrm{O}$ traço do concreto, incluindo o fator água-cimento e aditivos empregados, são fatores determinantes para a ocorrência desse fenômeno.

Algumas dessas situações estão ilustradas nas Fotos e Figuras apresentadas a seguir, que correspondem a grandes incêndios ocorridos na região metropolitana de São Paulo e que conduziram a tragédias que, em conjunto, provocaram um grande número de mortes.

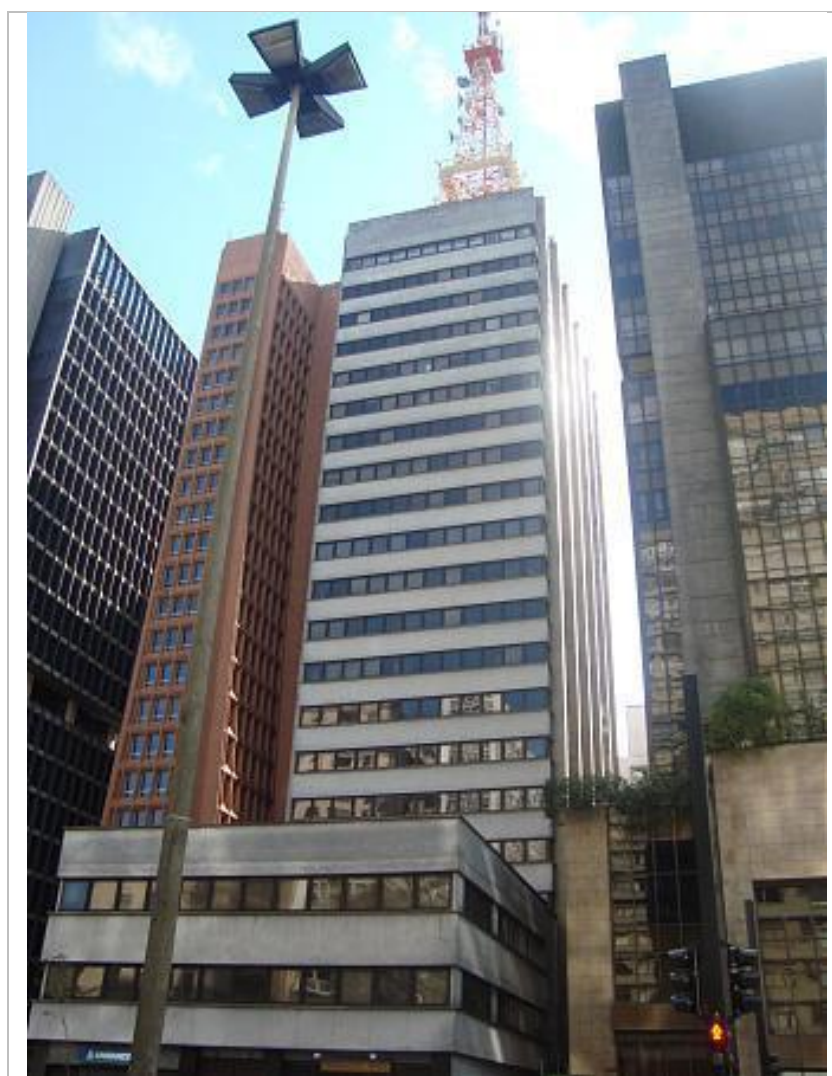

Foto 1 - Edifício Grande Avenida, destacando pódio frontal associado à torre com 22 pavimentos

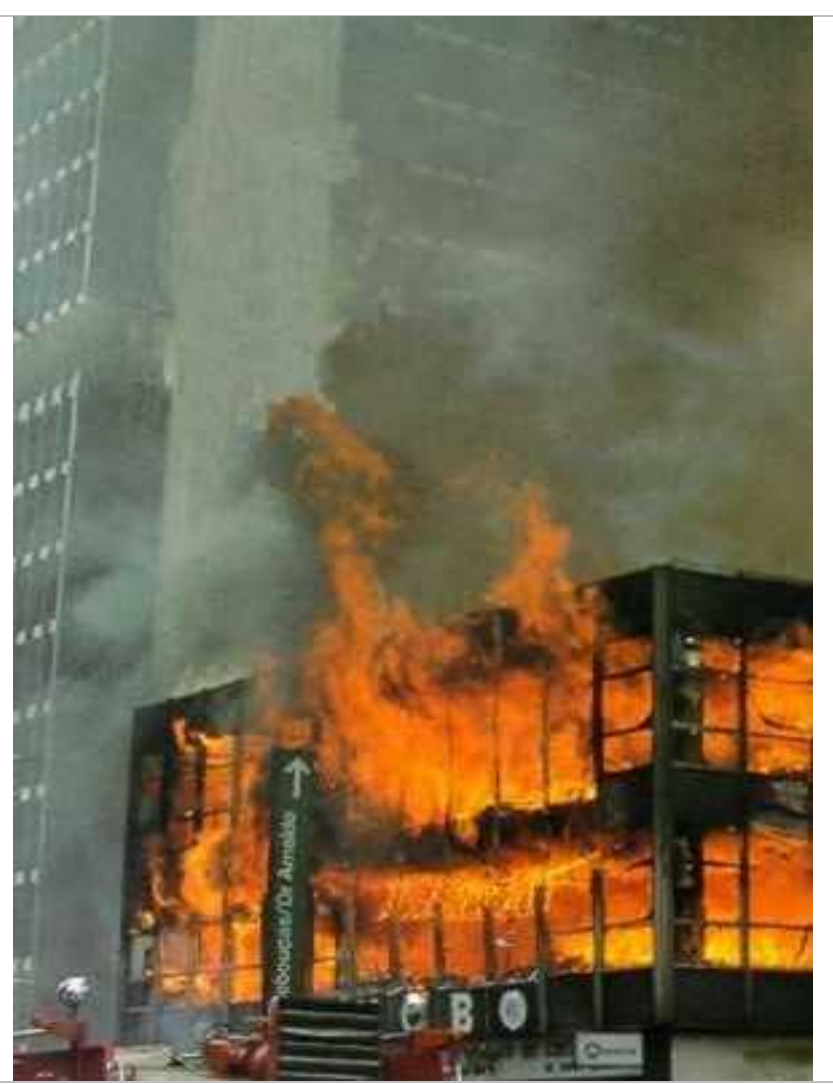

Foto 2 - Pódio do edifício Grande Avenida, submetido a incêndio em 14/02/1981 


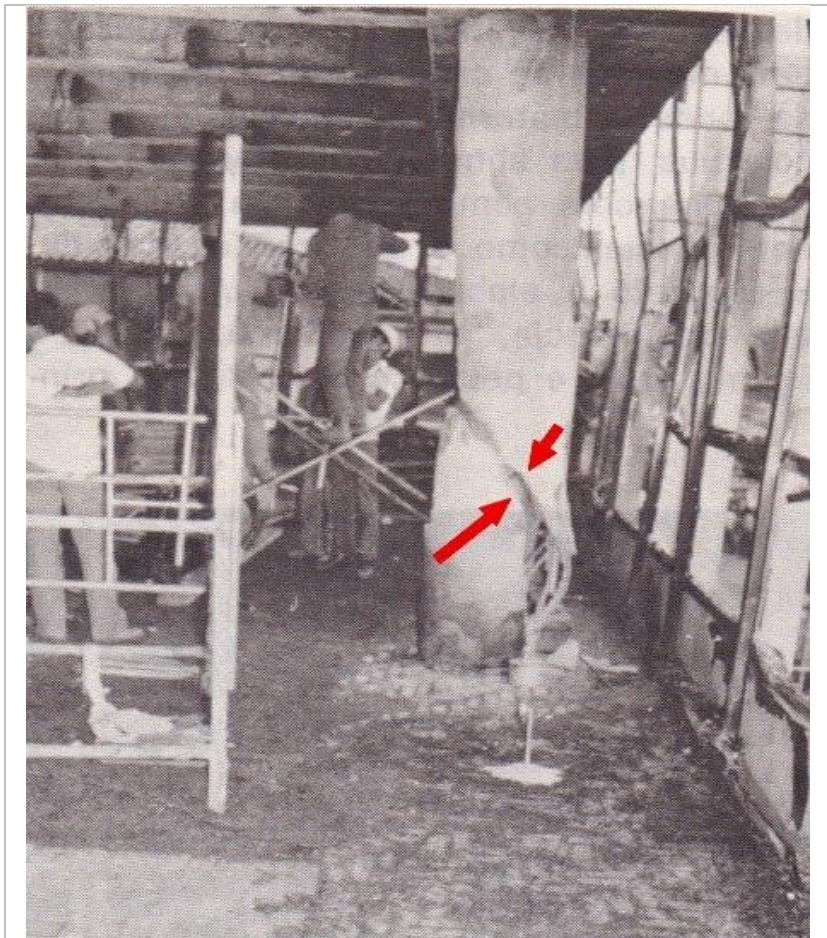

Foto 3 - Ruptura de coluna localizada no pódio do edifício Grande Avenida em razão de esforços de dilatação da laje

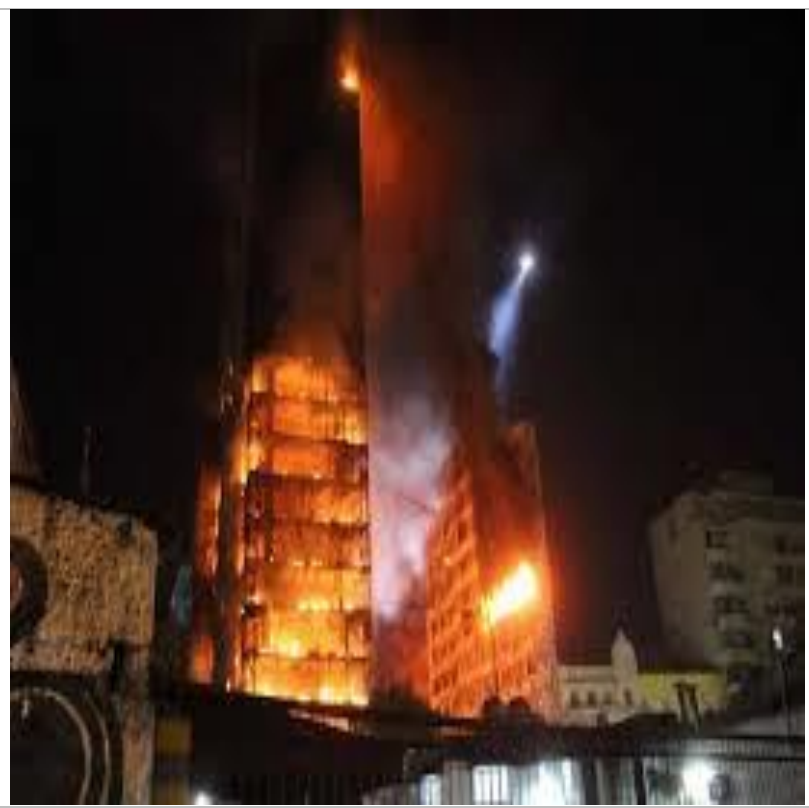

Foto 5 - Edifício Wilton Paes de Almeida submetido a incêndio em 01/05/ 2018

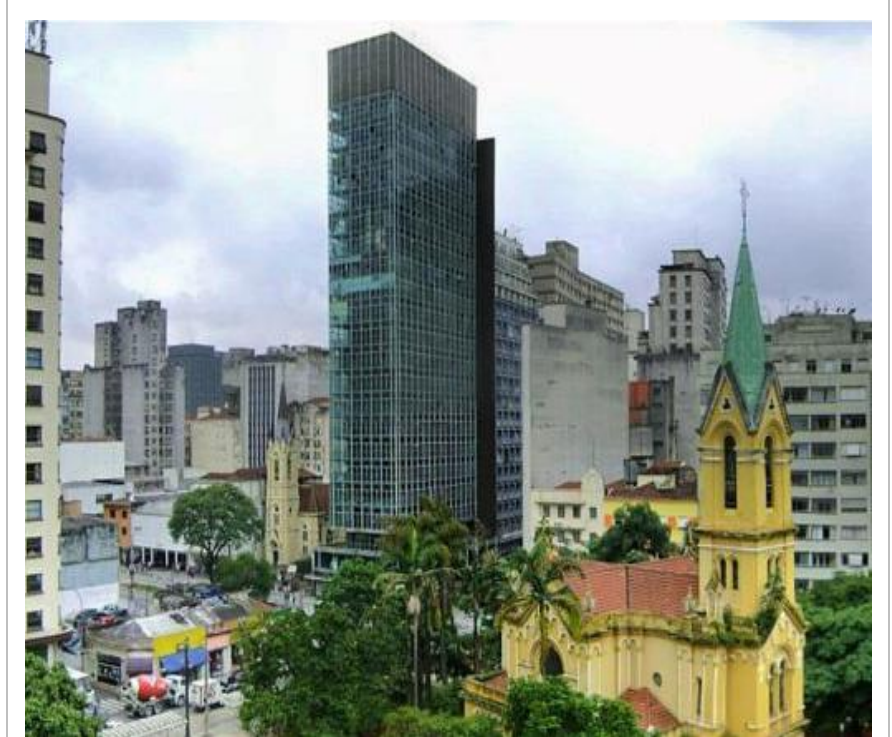

Foto 4 - Edifício Wilton Paes de Almeida, localizado no centro da cidade de São Paulo

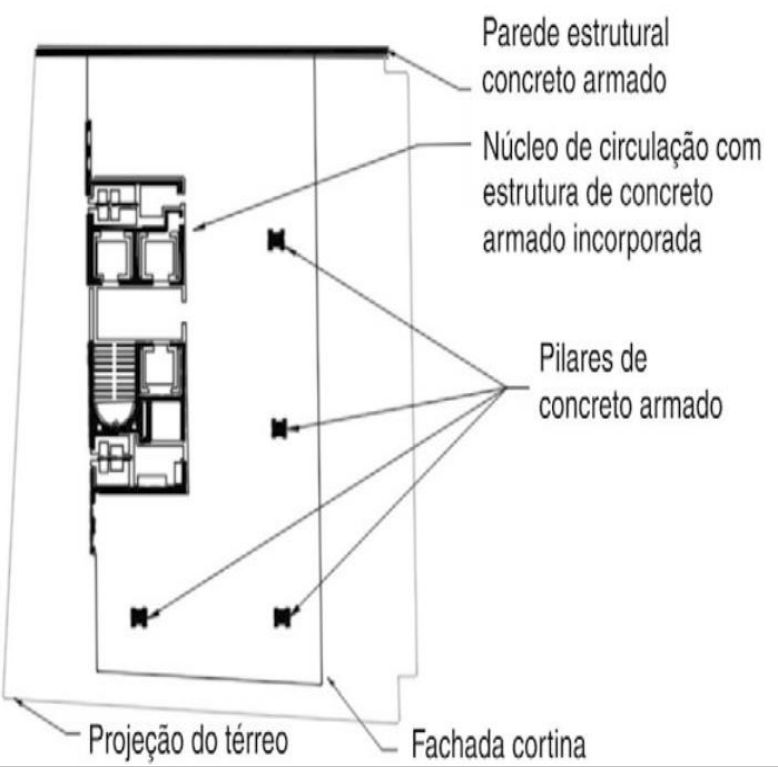

Figura 1 - Planta esquemática do pavimento tipo do edifício Wilton Paes de Almeida 


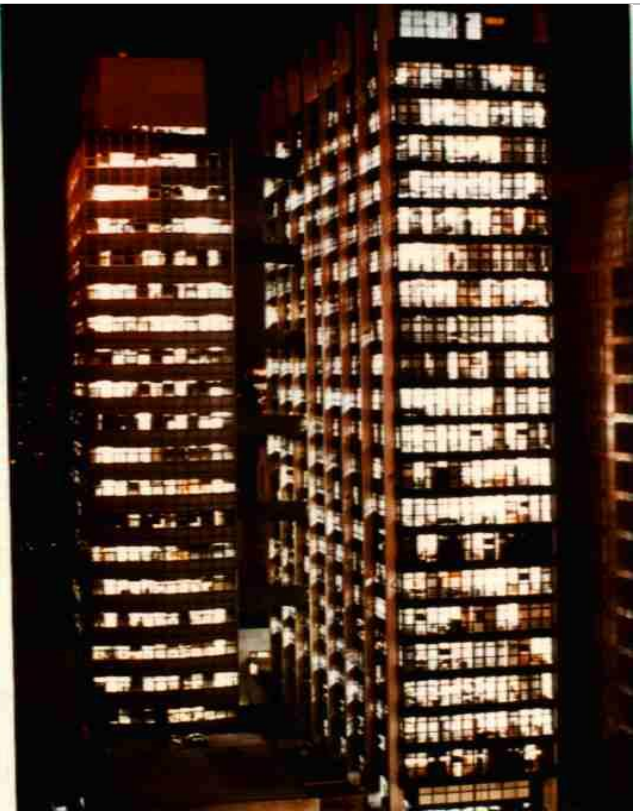

Foto 6 - Edifícios Sede I e Sede II da Companhia Energética de São Paulo - CESP

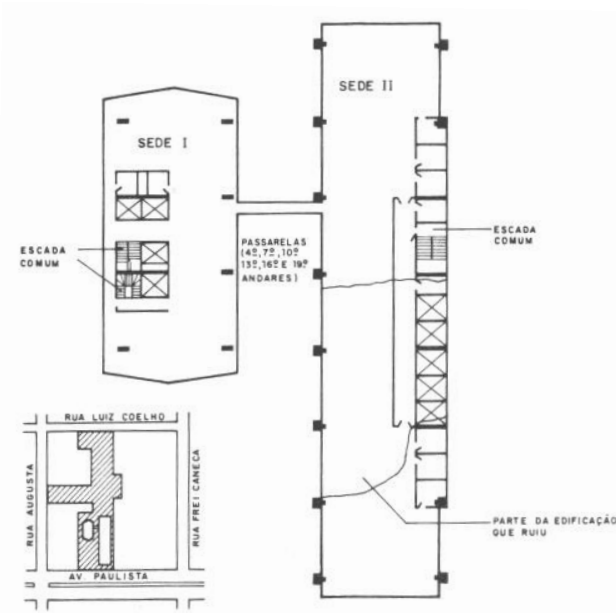

Figura 2 - Planta esquemática do pavimento tipo dos edifícios Sede I e Sede II da CESP mostrando setor que ruiu

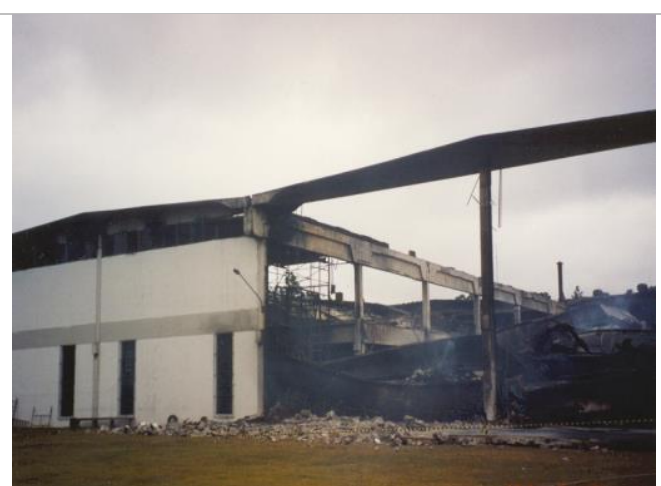

Foto 9 - Ruína de edifício com estrutura prémoldada submetida a incêndio

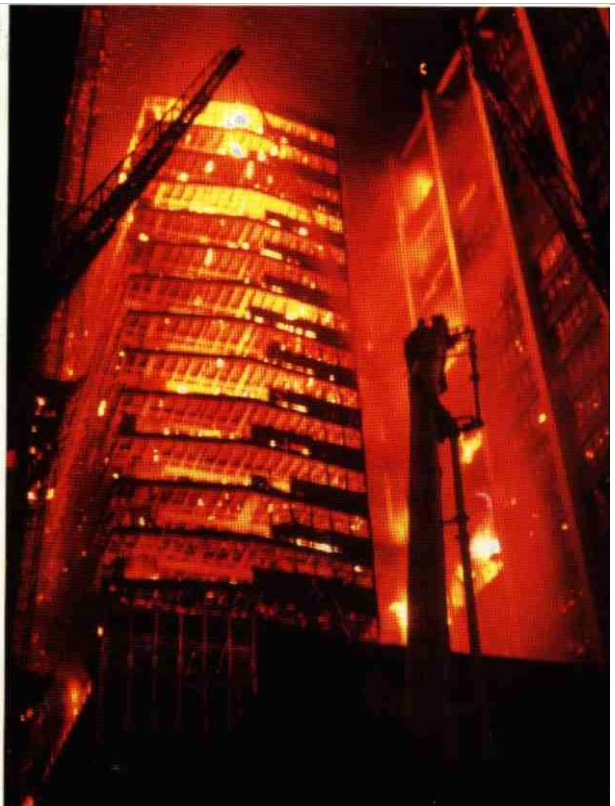

Foto 7 - Edifícios Sede I e Sede II da CESP submetidos a incêndio em 21/05/1987

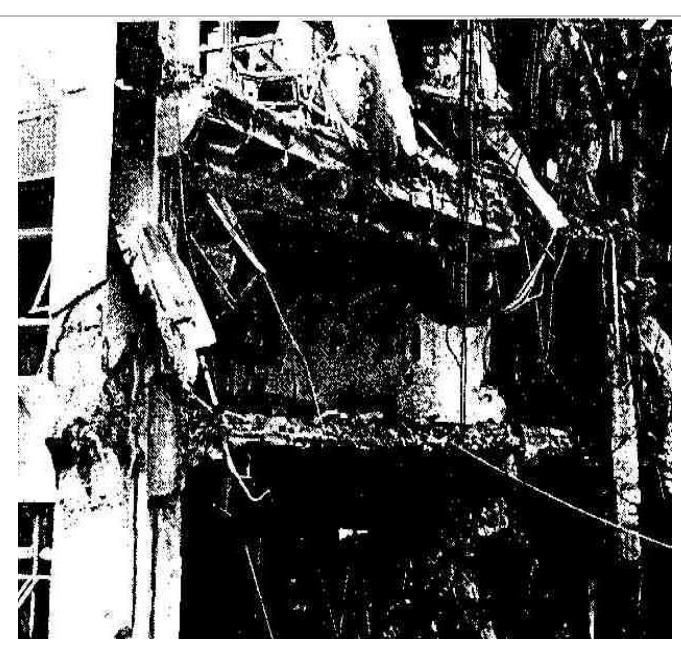

Foto 8 - Detalhe da ruína da estrutura de concreto do edifício Sede II da CESP

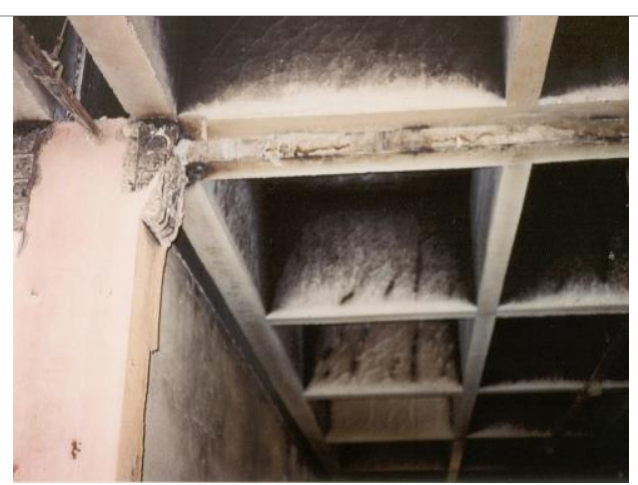

Foto 10 - Deslocamento de apoio de estrutura prémoldada submetida a incêndio 
Todas essas condições devem ser consideradas e solucionadas no projeto das estruturas de concreto, pois o colapso da estrutura de concreto não deve ocorrer em situação de incêndio, pois suas consequências catastróficas, especialmente no caso de edificações altas, são absolutamente inaceitáveis.

\section{ESTUDO DE CASO DE RUÍNA DE ESTRUTURA DE CONCRETO}

Um caso exemplar de ruína de estrutura de concreto correspondeu ao edifício Sede II da CESP em incêndio ocorrido no dia 21 de maio de 1987. Esse edifício integrava uma grande edificação, compondo um bloco com subsolos, pódio e duas torres. O subsolo apresentava três níveis, dois dos quais eram utilizados para estacionamento de veículos. O pódio era constituído pelo pavimento térreo e duas sobrelojas, que ocupavam toda a área do terreno. Acima desse pódio se localizavam duas torres, denominadas Sede I e Sede II que possuíam, respectivamente, 19 e 21 pavimentos. As duas torres apresentavam pavimento-tipo com dimensões de, aproximadamente, $12 \mathrm{~m}$ x $30 \mathrm{~m}$ e $12 \mathrm{~m}$ x $60 \mathrm{~m}$, respectivamente.

O forro do Edifício Sede I era composto por placas de fibras celulósicas aglomeradas e o forro do edifício Sede II consistia de placas de gesso. Sobre ambos foram mantidas as formas de madeira das lajes, que eram nervuradas. As fachadas das duas torres eram compostas predominantemente por caixilhos metálicos envidraçados.

O edifício Sede I apresentava duas escadas não enclausuradas, uma das quais alcançava até o $8^{\circ}$ pavimento. O edifício Sede II apresentava apenas uma escada, que era não enclausurada.

O incêndio se iniciou no $5^{\circ}$ pavimento do edifício Sede I, na rede elétrica de iluminação disposta sobre o forro combustível. $\mathrm{O}$ forro rapidamente se ignizou e as chamas se propagaram em sua superfície inferior. Porções ignizadas do forro se desprenderam sobre os materiais combustíveis contidos no escritório e os ignizaram. A inflamação generalizada no $5^{\circ}$ pavimento foi atingida muito rapidamente. O incêndio se propagou entre pavimentos no edifício Sede I com grande facilidade. Isto se deu por meio de dois caminhos: pelo interior do edifício, através das escadas; e pelo exterior do edifício, através das janelas e parapeitos de alumínio. A propagação vertical do incêndio foi tão rápida que todos os pavimentos do edifício, a partir do $5^{\circ}$, tiveram coincidência da fase de inflamação generalizada, ou seja, queimaram intensamente ao mesmo tempo.

Apesar da distância entre as fachadas dos edifícios Sede I e Sede II ser de 9,5 m, ocorreu a propagação do incêndio entre ambos por radiação térmica. O início do incêndio no edifício Sede II ocorreu de maneira intensa e concomitante em vários pavimentos. O incêndio não encontrou obstáculos nos pavimentos para atingir toda a área dos mesmos, visto que os andares só apresentavam subdivisões do lado oposto ao edifício ao edifício Sede I, onde se localizavam as escadas, os elevadores, as copas e os banheiros.

Aproximadamente duas horas após o incêndio ter se propagado para o edifício Sede II ocorreu o desabamento de sua parte central, conforme indicado na Figura 2. A estrutura do edifício era composta por um conjunto de pórticos múltiplos paralelos de concreto armado moldado in loco, cujos elementos horizontais consistiam de vigas $\mathrm{T}$, de grande seção e de grande rigidez que venciam vãos que variavam entre $8 \mathrm{~m}$ e $11 \mathrm{~m}$, aproximadamente. $\mathrm{O}$ afastamento entre os pórticos era de, aproximadamente, $8 \mathrm{~m}$. O travamento entre eles era promovido pelas lajes nervuradas dos pisos.

$\mathrm{O}$ incêndio, anteriormente à ruína do edifício Sede II, se desenvolvia mais intensamente nos andares superiores e a meia altura do edifício. Nessas regiões os elementos verticais dos pórticos estavam sujeitos a esforços decorrentes da dilatação térmica das vigas $\mathrm{T}$ e os seus materiais constituintes estavam perdendo gradativamente a resistência mecânica por estarem sendo aquecidos.

A ruína da região central do edifício se deveu ao incêndio que se desenvolvia na sua meia altura, tendo sido decorrente dos esforços de dilatação introduzidos por duas vigas $\mathrm{T}$ consecutivas, nos elementos verticais de seus respectivos pórticos. Esses dois pórticos consecutivos, apresentavam elementos verticais em uma das laterais do edifício, significativamente mais enrijecidos, visto que suas seções transversais eram maiores e conformavam as colunas que compunham o poço dos elevadores. As partes 
menos rígidas dos dois pórticos receberam esforços maiores decorrentes destas dilatações, regidas pela relação geométrica das seções das colunas de ambos os lados dos pórticos, e sofreram severo cisalhamento, rompendo-se.

O mesmo tipo de concepção estrutural foi adotado para o edifício Sede I. Apesar disso, os vão vencidos pelas vigas que compunham os pórticos múltiplos eram significativamente menores, alcançando cerca de 4,5 m onde havia distinção entre as seções dos elementos verticais do pórtico, e as vigas apresentavam seções menores que as do edifício Sede II. Esta situação não determinou o surgimento de esforços cortantes críticos nos elementos verticais dos pórticos.

Verificou-se no edifício Sede I, que os elementos estruturais horizontais (vigas e lajes) apresentavam dois problemas capazes de comprometer seriamente a estabilidade da estrutura em situação de incêndio. Um deles se relacionava ao cobrimento das armaduras, de maneira geral muito reduzido, estando junto à superfície do concreto em algumas regiões. $\mathrm{O}$ outro se relacionava às seções transversais reduzidas das vigas das lajes nervuradas, que eram insuficientes para assegurar resistência ao fogo superior a $1 \mathrm{~h}$. Com isso, parte significativa dos elementos estruturais horizontais sofreu grande deformação.

Apesar de ter ocorrido o desabamento em apenas uma parte da estrutura do edifício Sede II, dividindoo em dois, o que restou de sua estrutura e também da estrutura do edifício Sede I, sofreu danos gravíssimos, de forma que, após o incêndio, havia o risco iminente de desabamento total dos dois edifícios. Tal situação justificou a necessidade urgente de demolição dos dois edifícios.

A fragilidade da solução estrutural das duas edificações frente à situação de incêndio, associada à ausência de compartimentação vertical, mostra claramente o quanto o sistema estático adotado para a estrutura das duas torres era frágil. A ruína ocorrida evidencia que essa solução estrutural, sob o ponto de vista da segurança contra incêndio, deve ser evitada.

Parte das situações, relativas às estruturas dos dois edifícios, aqui relatadas são mostradas nas Fotos e Figura apresentadas a seguir e na Figura 2 e Foto 8, apresentadas anteriormente. Fica claro, em relação ao edifício Sede II, que os esforços de dilatação das vigas cisalharam as colunas de dois pórticos, promovendo o desabamento da parte central da torre.

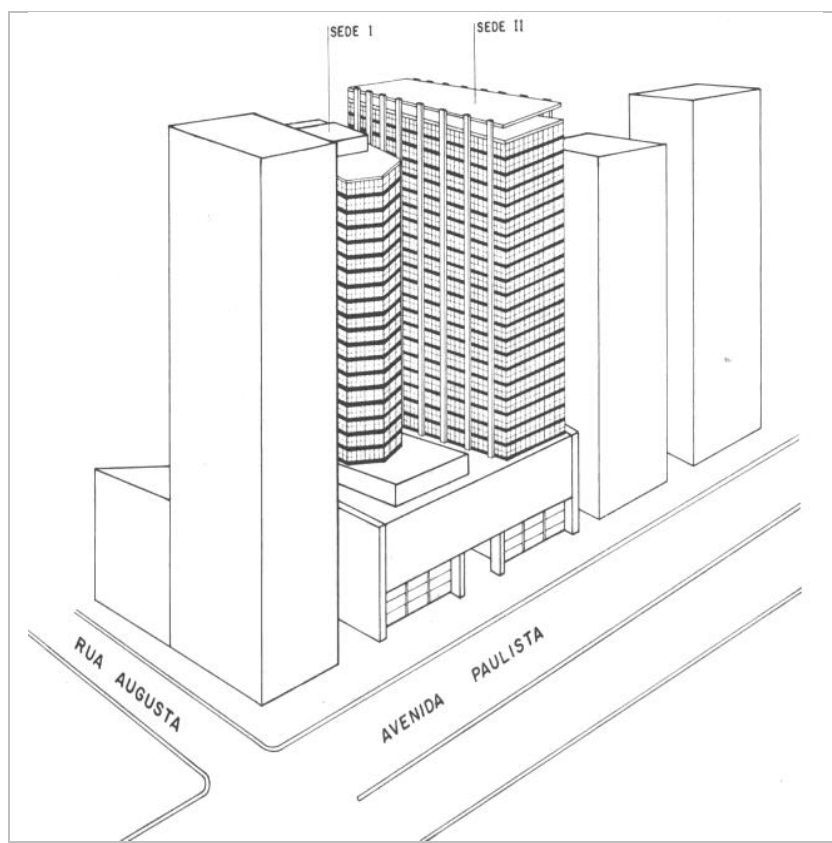

Figura 3 - Bloco afetado pelo incêndio: Pódio e edifícios Sede I e Sede II

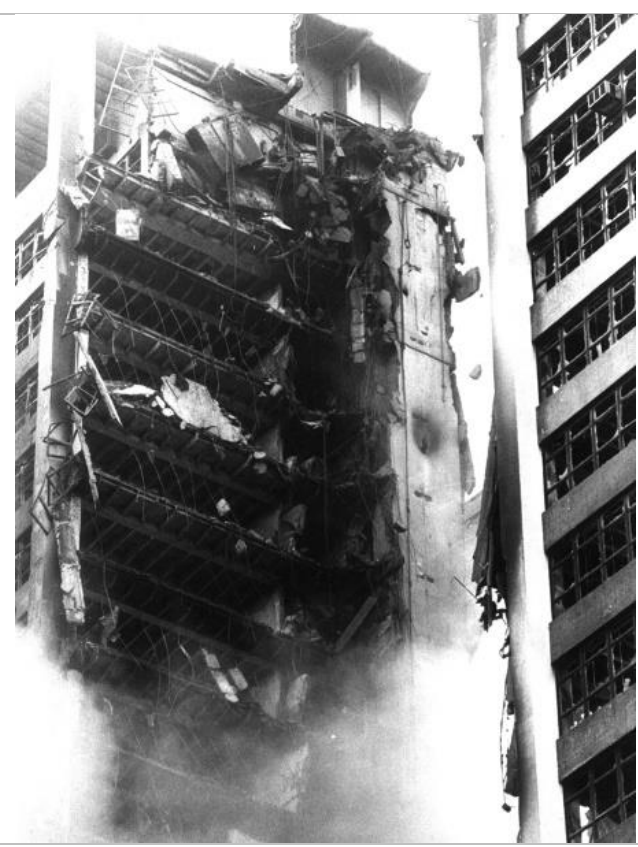

Foto 11 - Detalhe da ruína da estrutura de concreto do edifício Sede II, mostrando as duas partes remanescentes da torre 


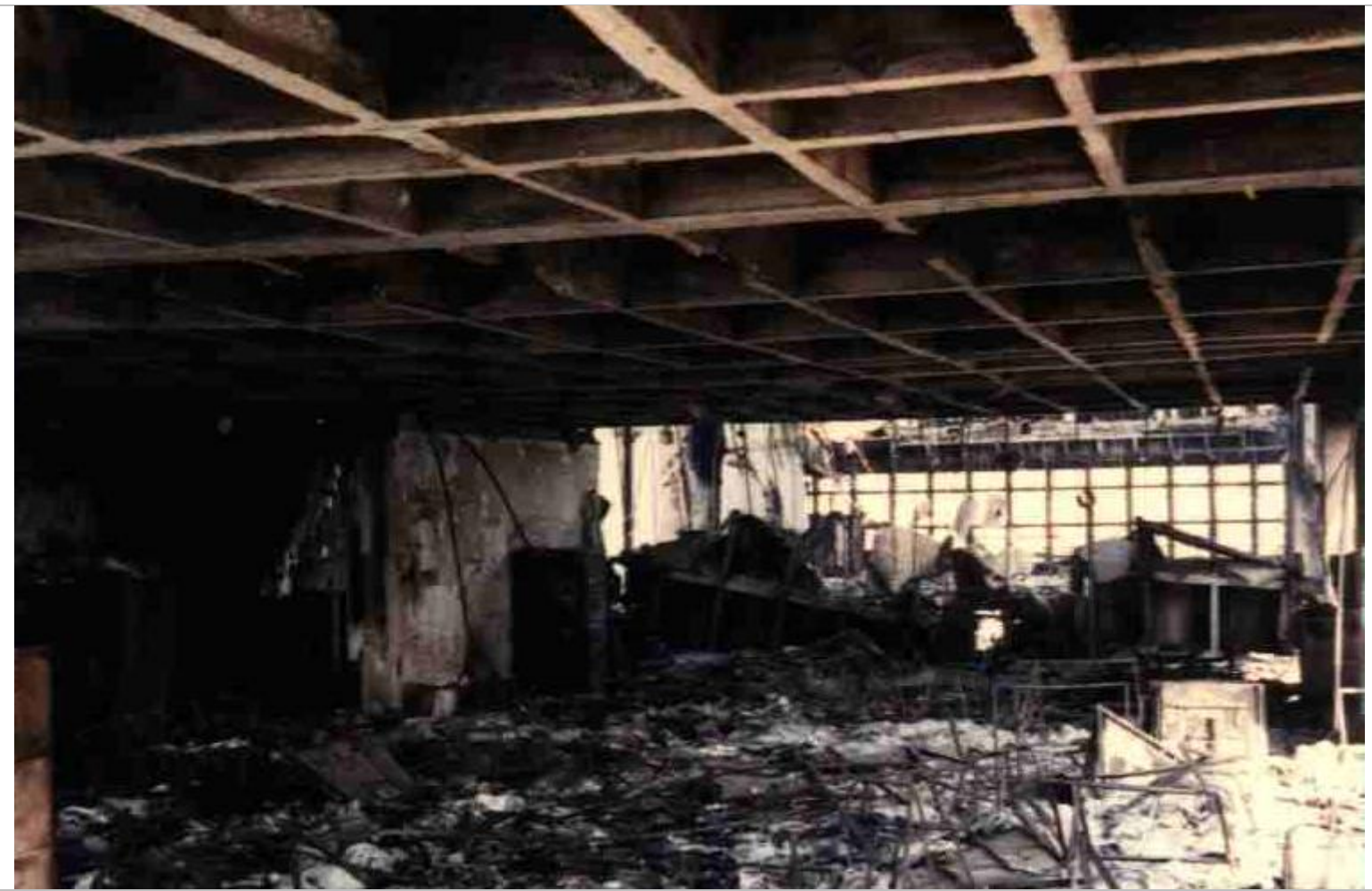

Figura 12 - Vista da parte frontal da estrutura do edifício Sede II, a partir de sua parte posterior, com destaque para o vazio, deixado pelo desabamento da parte central

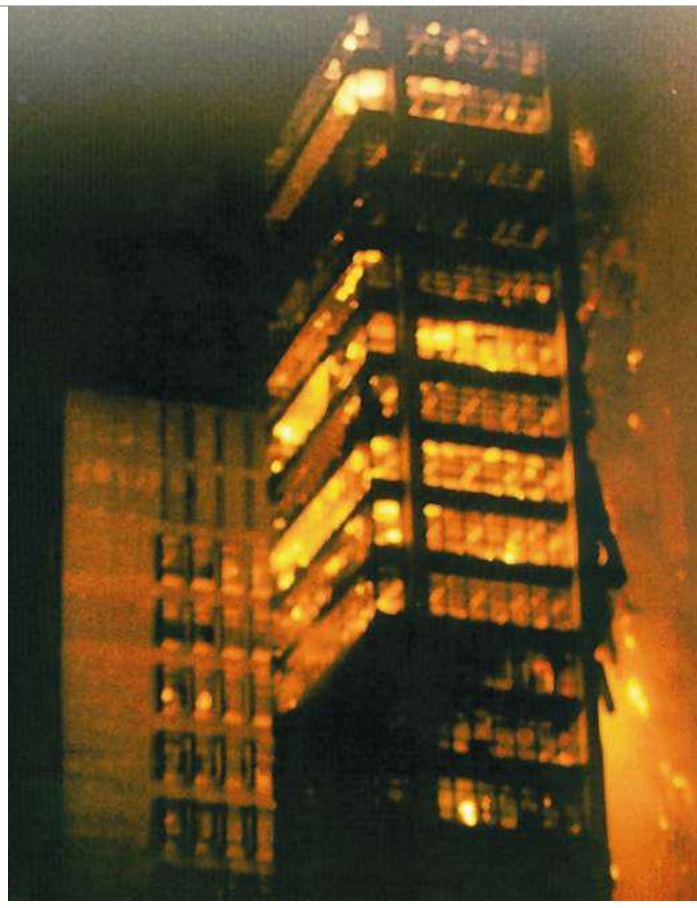

Foto 13 - Parte frontal remanescente do edifício Sede II

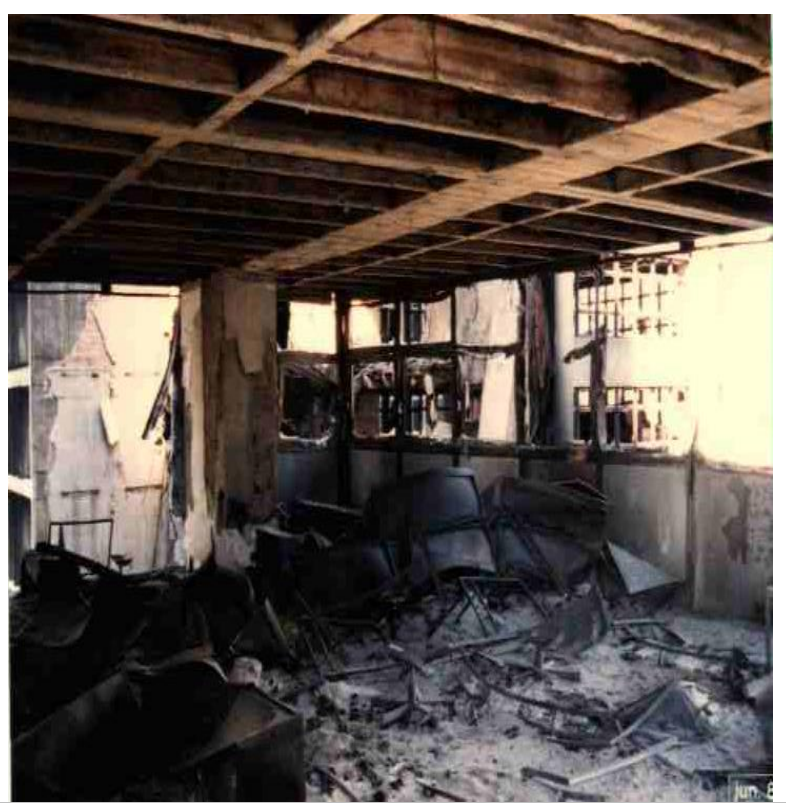

Foto 14 - Estrutura do edifício Sede I danificada pelo incêndio

\section{CONSIDERAÇÕES FINAIS}

Os casos de colapso apresentados afetaram edifícios construídos quando não havia no Brasil exigências de atendimento compulsório destinados a garantir condições adequadas de segurança contra incêndio. 
Atualmente existem regulamentações, como o Decreto Estadual $\mathrm{n}^{\mathbf{0}}$ 63.911/2018 do Corpo de Bombeiros, com detalhamento estabelecido na Instrução Técnica nº 08/2019 - Resistência ao Fogo dos Elementos de Construção - que determina em grande parte das situações, entre as quais se destacam os casos dos edifícios de maior porte, que as estruturas de concreto e também de qualquer outro tipo de material (aço, madeira e alvenaria estrutural) sejam projetadas e executadas de forma a apresentarem resistência ao fogo, ou seja, de forma a serem capazes de suportar a ação do incêndio preservando a estabilidade estrutural dos edifícios.

Apesar disto, a norma citada nesta regulamentação, relativa ao dimensionamento de estruturas de concreto em situação de incêndio, deve ser aprimorada urgentemente e os projetistas devem se conscientizar da importância de atribuir às estruturas capacidade real de suportar a ação de um incêndio preservando a estabilidade das edificações.

A regulamentação citada, que serve de referência a outras regulamentações existentes no Brasil, deve ser aprimorada e garantir uma abordagem consistente capaz de evitar que as estruturas devidamente dimensionadas sejam afetadas por ações extremamente severas, representadas, entre outras situações, por grandes porções da estrutura expostas, concomitante ou sucessivamente, à ação do incêndio.

\section{REFERÊNCIAS}

ABNT/CB-002 Construção Civil. (2012). ABNT NBR 15200: Projeto de estruturas de concreto em situação de incêndio.

Corpo de Bombeiros da PMESP. (2019). Instrução Técnica $n^{o} 08$ - Resistência ao fogo dos elementos de construção.

Corpo de Bombeiros da PMESP. (2019). Instrução Técnica $n^{\circ} 09$ - Compartimentação horizontal e compartimentação vertical.

Corpo de Bombeiros da PMESP. (10 de dezembro de 2018). Decreto Estadual nº 63.911.

Helene, P. R. (2018). Incêndio e Colapso do Ed. Wilton Paes de Almeida. Lições Aprendidas. 